THURSDAY, APRIL 20, $187 \mathrm{I}$

\section{APE RESEMBLANCES TO MAN}

THE Zoological Society can hardly fail to derive 1. decided material advantage from the publication of Mr. Darwin's "Descent of Man." It has been said that already there is a perceptible increase in the visitors to the monkey-house, though an early spring has no doubt co-operated with scientific zeal in the promotion of pilgrimages to the Regent's Park, undertaken in the interest of a more than Chinese worship of ancestors. These visits would, perhaps, be considerably increased if it were very widely known that a fine specimen of a closely-related structural ally was there to be seen and heard, and one the resemblance of which to us has, I venture to think, not been generally appreciated sufficiently. I allude to the fine specimen of the Hoolock Gibbon which has been some time at the Gardens, and which appears to rejoice in good health, good temper, and good voice.

Differing so greatly and fundamentally as I do from Mr. Darwin, it is with sincere pleasure that I give my testimony to the correctness of his appreciation of the value and bearing of man's bodily structure on his zoological position. There can, I think, be no doubt that his frame is so closely related to that of the anthropoid division of the Old World apes, that to accord to it the rank of a family is to go to the extreme of maintainable distinction. Descending, however, to smaller divisions, it is generally taken for granted that the palm of resemblance to ourselves can be disputed by the Orang (Simia), or by the African genus Troglodytes (which includes both the Gorilla and Chimpanzee) alone. The third member, however, of the anthropoid Simian Graces-the genus Hylobates (long-armed apes or Gibbons)-has claims to advance for an award in its favour which I am disposed to consider not unworthy of consideration. Assuming, for argument's sake, the truth of Mr. Darwin's hypothesis that man's body was derived by natural generation from some form of ape, it may, I think, possibly be the case that we have in the existing Gibbon the representative of an ancestor more in the direct line than either the Orang or the African forms, and this in spite of the many points in which the Gibbon recedes yet further from human structure. For though it is indisputable that we can enumerate a greater number of points of resemblance between man and Simia or Troglodytes than between man and the Gibbons, while it would be easy to draw out a catalogue of details by which the last-named apes differ more from man than do Simia and Troglodytes, nevertheless there are certain points in which the Gibbon genus resembles Homo which are striking and perhaps significant. Although the enormous length of the arms disguises the resemblance, yet the proportions of the Gibbon's frame (as in some respects long ago pointed out by Professor Huxley) are singularly human. The length of the leg as compared with the trunk, and the form and proportion of the bony thorax, are points which may be mentioned. Again, a Gibbon (the Siamang) is the only ape which possesses that striking human feature-a true chin. The slight prominence of the nose too is also very VOL. III. remarkable, a point which has not escaped the notice of Mr. Darwin, and is to be seen in the living specimen here referred to. Again, the power, quality, and compass of the voice are qualities justly dwelt upon by the lastnamed author; and, finally, the gentle, yet quick and active nature of the Gibbon is eminently noteworthy.

On the other hand the Orang is a very specially organised, quite aberrant beast (as I have elsewhere endeavoured to show), and the brain in the genus Troglodytes is considered by Gratiolet to indicate altogether other relationships. Now it is not impossible, on the hypothesis assumed, that the Orang, Gorilla, and Chimpanzee may be types which have really diverged further from that anthropoid root-form which most nearly resembled man than has the Gibbon, and that adaptations to conditions may have superinduced many of those human resemblances which at present characterise them. It seems difficult, certainly, to apply this view to some details, such e.g. as the vaginal process of the temporal bone on the basis cranii. On the other hand, it is not in the highest but in one of the lowest of the Simiadæ that I have found an anchylosed styloid process to be occasionally present.

A very interesting fact is the great Miocene Gibbon of Europe, the Dryopithecus, which goes to confirm the view here suggested as to the dignity of Hylobates; but of course we can but speculate inconclusively till Palæontology furnishes us with the nearest extinct representatives of the Gorilla, Chimpanzee, and Orang.

To prevent misconception, I may add that fully recognising the truth of Mr. Darwin's appreciation of man's zoological position, which I have ever maintained and indeed laboured to support, I none the less completely differ from him when I include the totality of man's being. So considered, Science convinces me that a monkey and a mushroom differ less from each other than do a monkey and a man.

\section{St. George Mivart}

\section{THE COLLECTION OF INVERTEBRATE ANIMALS IN THE FREE PUBLIC MUSEUM, LIVERPOOL}

\section{II.}

W ${ }^{E}$ have mentioned in a previous article * the division of the series of Invertebrate Animals in the Liverpool Museum into 216 groups. The following is the plan of arrangement adopted in connection with each group. Wherever circumstances permit the plan includes: (1) A printed schedule. (2) Exotic species. (3) British representatives. (4) The printed tablet. (5) Earliest fossils. (6) Diagrams and other illustrations. (7) Species and varieties on a more extended scale.

(I) The schedule, of which an example follows, is printed in large type, and is placed conspicuously at the head of the drawer; it is designed to show the derivation of the group, e.g.-

$$
\text { " Group } 198 .
$$

SUB-KINGDOM-Annulosa, Skeleton external, ringed. Province-Arthropoda, Limbs jointed.

Class-Insecta, Legs six.

SU B-CLASS-Metabola, Transformations complete.

ORDER-Lepidoptera, Wings with scales.

$$
\text { * See Nature, vol. iii. p. } 202 .
$$


SUB-ORDER-Rhopalocera, Horns clubbed at the apex. FAMILY-Papilionida, Middle nerve of fore-wing fourbranched."

The next sub-division appears on the tablet as the distinctive title of the 198th group.

"GENUS-Ornithopiera and allies, Bird-winged butterflies. About twenty species known."

(2) The further portion of the drawer, to the extent of three-fifths (more or less) of the whole area, accommodates from ten to sixty exotic species; such as are most distinct being preferred. A reference to the authority accompanies many of the generic, sub-generic, and specific names. The locality, when copied from $a_{a}$ monograph, is stated simply; but when it is known where the specimen has been collected, the word "from" is added-e.g. "from Madagascar."

(3) The nearer right-hand corner of the drawer is occupied by representatives of the group indigenous to Britain. Some groups have no British representatives; in others-e.g. Noctuce genuince, a selection from the British species fills three-fourths of the drawer. Amongst these, foreign specimens of rarities are admitted, but in all such cases the words " exotic specimen" are appended to the name on the label.

(4) The nearer left-hand corner is assigned to a few fossils showing the earliest appearance of the group in the Geological record. In one or two instances, e.g. Hippurites, the entire group is fossil, in others, of course, fossils are absent.

(5) Between these two latter sections of the drawer is placed the printed tablet, about the size of an octavo page. It exhibits an attempt to describe some of the salient points in the life-history of the group. Here, and throughout the series, some attention has been given to ensure legibility; names and descriptions being of much less value when they cannot be read easily.

(6) The upright portion of the table case over each drawer is given to miscellaneous illustrations of the group. The series includes drawings and photographs of structure and anatomy, economic products, silk in various stages, marine and freshwater pearls, cameos, from the rough medallion cut from the shell to the finished work, polished shells, and sections showing the interior of shells, eggs, preserved larvæ and pupæ, preparations in spirits, examples of mimicry, nests of Hymenoptera, galls and their tenants, timber and stone pierced by molluscs, crustacea and insects, distorted growths, healed fractures, coral beads, British and exotic specimens of fungi growing on pupæ, and many other objects of interest.

(7) The blocks on which some of the table cases rest are fitted with drawers suitable for receiving an extended series of species and varieties, valuable only to the student, and intended to be seen only on application to the Curator. Very little progress has been made in carrying out this portion of the plan, which has, however, the good effect of rendering it quite needless to overcrowd the groups with insignificant species.

The difficulties attending the formation of the series of specimens have not been very great. Collections have been presented to the Museum by several friends of natural science, amongst whom may be mentioned $\mathrm{Mr}$. Samuel Smith, of Liverpool, the donor of a collection of shells rich in generic forms and in costly rarities of the highest beauty. Mr. Moore has been successful in establishing friendly communications with many captains of merchant vessels sailing from the port of Liverpool, some of whom have been supplied by the committee with dredges and collecting apparatus, and have become enthusiastic naturalists. In recognition of their services several of them have been received as Associate Members of the Literary and Philosophical Society of Liverpool, a distinction which seems to be highly appreciated by them. Something has also been done in the way of exchanges; but a large proportion of the whole series has been purchased specimen by specimen. No object has been purchased simply on account of its rarity, but at the same time no reasonable expense has been spared in procuring the most beautiful and perfect examples.

A few general remarks on the subject of expense may be permitted : details will gladly be communicated to inquirers connected with museums. Few collections exhibited to the public will bear comparison with corresponding series contained in private cabinets. Why should this any longer be permitted? It may arise, in part, from the impression that in public museums it is unnecessary to spend much on specimens. There can be no excuse for extravagance, but economy may be pushed too far. The trouble and great risk of collecting in tropical climates must often be very inadequately represented by the apparently high prices asked for the chief desiderata, and the rest of a collector's stock may remain on his hands for years. Again, if a genus or a group is illustrated in nature by a great variety of beautiful forms, this surely is a biological fact which may claim, on scientific grounds, to be fairly and appropriately represented. Even on the most severe estimate of what is necessary for an educational series, something must be allowed simply for the sake of beauty and attractiveness ; that is to say, if museums are to avoid the fate of certain parochial lending libraries which contain only such books as everybody ought to like to read. Naturalists of the very highest scientific standing, much more ordinary observers, are greatly under the influence of beauty of form and colour. Even Mr. Wallace himself would not have been so near syncope at the sight of a new Brachelytron as he seems to have been on his first introduction to the magnificent $O$. Crosus. Why, moreover, should the public be taught to esteem art treasures as so much more valuable than the choicest productions of nature? One hears of a pair of vases being sold for 2,000l., a sum which would provide twenty first-rate table cases, and stock them with very fair illustrations of the whole of the invertebrate groups. It is a happy circumstance that a museum of common objects may, at a trifling cost, be established in almost any village, and with judicious local influence brought to bear upon it, may prove both useful and creditable; but why should not wealthy communities, possessing endless drawing-rooms ablaze with costly decorations, exercise something of a corresponding liberality towards the museum which is the representative of their appreciation of that which is higher than the highest art?

Considerable difficulty has been found in selecting appropriate materials for the printed tablets. Many of the chief continental authorities on the Invertebrata, admirable as are their works for the purpose of identifying species, afford scarcely a line of information on the life history of 
the objects they so grandly figure and often so elaborately describe. Even the reports of scientific expeditions may frequently be searched in vain for this kind of information, which has to be gleaned from authorities not always trustworthy, from scattered papers, or from books of travel such as have been issued in this country on the Malay Archipelago and the River Amazon. It is mortifying to exhibit forms distinguished by extraordinary developments of structure, and to be able to say nothing on associated habits. Such strange developments were once considered to be mere freaks of nature, but no one now doubts their having a biological and even a genealogical significance. What a field is is here opened! How little of the biology of a new form has been exhausted when it has been collected, named, described, figured, and even dissected ! Scientific treatises have prepared the foundation for a solid knowledge of the subject, but there would be occasion for regret if biology should ever come to be regarded by students in an aspect too exclusively histological or even physiological, if such a view operated to the prejudice of genuine out-of-door observations. The greatest advance in Natural History made in the present, or perhaps in any other generation, has been mainly accomplished by two observers who are pre-eminently life-historians.

Little need be said of the miscellaneous illustrations contained in the upright portion of the table-cases. They seem to be very successful in engaging the attention of visitors of all classes-a point which is felt to be of prominent importance where the admissions amount to about 2,000 daily. What brings them here? is a question which again and again suggests itself. Reduce the number by all the idlers and sight-seers who, no doubt, constitute a large proportion of the gathering; still, if only 100 or even 50 seek some kind of instruction, even these in the course of a year form a large and teachable class. As a firm believer in the humanising effect of an intelligent interest in Natural Science, to myself the grand museum problem seems to be, how to make such an institution most beneficial to the greatest number.

HENRY H. HIGGINS

\section{PRE-EUCLIDIAN GEOMETRY}

Die Geometrie und die Geometer vor Euklides. Von Prof. C. A. Bretschneider. (Leipzig : B. G. Teubner, I870. London: Williams and Norgate.)

T NTIL the appearance of this book, Montucla's celebrated "History of Mathematics" contained almost all that was known about the early history of Mathematics up to the present time. Later historians, even the careful Chasles, have almost exclusively copied him, without taking the trouble of searching the Greek writings for themselves. Montucla's remarks, however, are not only meagre, they are even not always correct. For this reason Prof. Bretschneider has collected all important passages in Greek writings which refer to the state of Geometry in Greece in the time before Euclid. This author is the first of whom complete works have reached us; with him, therefore, a History of Geometry begins. With regard to the ante-Euclidian times we cannot advance beyond conjectures, and these will always depend more or less upon the individuality of the historian.
Perfectly aware of this, Prof. Bretschneider gives in the little volume before us, of about I 80 pages, not merely his conclusions, but he adds the whole material which he has collected. Instead of simply referring to an author, he quotes in extenso the original Greek text, and adds translations. Thus every reader is at once enabled to form his own opinion, which, we feel assured, will in most cases agree with that of our author.

In the first section Prof. Bretschneider considers the Geometry of the Egyptians, and tries to make out how far their knowledge extended. He protests against the old opinion that they possessed only the very first notions of geometry, and that the Greeks did not obtain anything from them worthy of the name of science. He refutes equally strongly the statement of some modern writers, who maintain that the Egyptians knew not only all that Euclid gives in his Elements, but were even acquainted with the theories of quadratic equations and of conic sections. According to him geometry originated in Egypt, where it was cultivated for practical purposes. It was rather an art of mechanical drawing than a science proper. The results obtained were collected in the form of fixed rules, always ready for use, most of them probably strictly proved others perhaps resting on experience only. Those collections of rules were at an early age included in the religious canons. Any alteration, any improvement, was thus alrnost impossible, especially as the only cultivators of Science, the priests, would take a secondary interest only in anything not strictly connected with religion. Thus it is not to be wondered at that geometry remained for thousands of years in the same state, till the unfettered genius of the Greek nation began to cultivate it, and then the progress was a most rapid one.

It is, however, remarkable, although natural enough, that the Greeks retained to a certain extent the form into which Egyptian priests had cast their propositions. For this fact there exists a testimony in a papyrus at the British Museum, formerly in the possession of the late Mr. Rhind, which contains a pretty complete treatise on Applied Mathematics, in the shape of problems which are stated in that peculiar form with which we are so well acquainted through Euclid's Elements. Dr. Birch, who has given an account of it, dates it as far back as $3400-$ 3200 B.C. Prof. Bretschneider traces many other peculiarities in Euclid's Elements-for instance, the order of propositions-back to the same source; so that the Egyptian priests, who lived about 6000 years ago, have, in the most direct manner, influenced the mode of teaching geometry in English schools even at the present time.

The extent of Ægyptian Geometry is estimated as follows:-the theory of angles and parallel lines; the construction of triangles, parallelograms, and trapezoids from given parts, and the determination of their areas; the elementary propositions of the circle together with the inscribed regular polygons; - this is about the sum total of Plane Geometry. In Solid Geometry their knowledge was limited to the first notions about lines perpendicular to a plane, and the theory of parallel lines and planes in space. They were acquainted with the existence of prisms, regular pyramids of four sides, of the right cone and cylinder, the sphere, and of the regular solids with the exception of the dodecahedron, which is the only one discovered by Pythagoras. Of the properties of 